\title{
Some Properties of Fuzzy Soft Groups
}

\author{
Dr. N. Sarala ${ }^{1}$ B. Suganya ${ }^{2}$ \\ ${ }^{1}$ Department of Mathematics, A.D.M college for women, Nagapattinam (India), \\ ${ }^{2}$ Department of Mathematics, Bharathidasan University Model College, Vedaranyan (India)
}

Abstract: In this paper, the concept of fuzzy soft group is extended and some of their properties and structured characteristics are discussed and studied. Some important results are proved. Some important results are proved.

Keywords: Soft set, Fuzzy Soft Set, Soft Group, Fuzzy Soft Group, Fuzzy Subgroup, Soft Homomorphism.

\section{Introduction}

Researchers in economics, engineering, environmental science, sociology, medical science and many other fields deal daily with the complexities of modeling uncertain data. Rosenfeld [10] proposed the concept of fuzzy groups in order to establish the algebraic structures of fuzzy sets.

The main purpose of this paper is a basic version of soft group theory, which extends the notion of a group to include the algebraic structures of soft sets.

In this paper begins by introducing the basic concepts of fuzzy soft set theory then we discuss a basic version of fuzzy soft group theory, which extends the notion of a group to the algebraic structures of fuzzy soft sets. A fuzzy soft group, on the other hand, is a parameterized family of fuzzy subgroups.

\section{Preliminaries}

In this section, we first recall the basic definitions related to fuzzy soft sets which would be used in the sequel.

\section{Definition2.1. Soft set [7]}

Suppose that $\mathrm{U}$ is an initial universe set and $\mathrm{E}$ is a set of parameters, let $\mathrm{P}(\mathrm{U})$ denotes the power set of $\mathrm{U}$.A pair $(\mathrm{F}, \mathrm{E})$ is called a soft set over $\mathrm{U}$ where $\mathrm{F}$ is a mapping given by $\mathrm{F}: \mathrm{E} \rightarrow \mathrm{P}(\mathrm{U})$.

Clearly, a soft set is a mapping from parameters to $\mathrm{P}(\mathrm{U})$, and it is not a set, but a parameterized family of subsets of the Universe.

\section{Definition 2.2. Fuzzy soft set [7]}

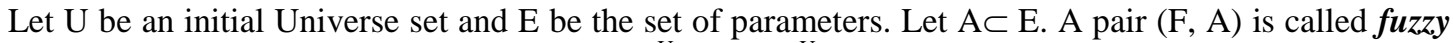
soft set over $\mathrm{U}$ where $\mathrm{F}$ is a mapping given by $\mathrm{F}: \mathrm{A} \rightarrow \mathrm{I}^{\mathrm{U}}$, where $\mathrm{I}^{\mathrm{U}}$ denotes the collection of all fuzzy subsets of U.

\section{Definition 2.3. Fuzzy soft class [9]}

Let $\mathrm{U}$ be an initial Universe set and $\mathrm{E}$ be the set of attributes. Then the pair (U,E) denotes the collection of all fuzzy soft sets on $U$ with attributes from $E$ and is called a fuzzy soft class.

Definition 2.4. Union of fuzzy soft sets [9]

Union of two fuzzy soft sets $(\mathrm{F}, \mathrm{A})$ and $(\mathrm{G}, \mathrm{B})$ in a soft class $(\mathrm{U}, \mathrm{E})$ is a fuzzy soft set $(\mathrm{H}, \mathrm{C})$ where $C=A \cup B$ and

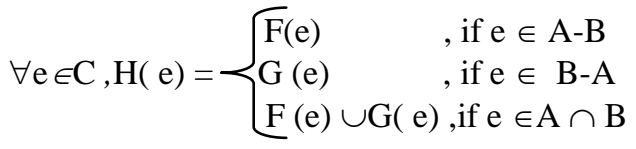

and is written as $(\mathrm{F}, \mathrm{A}) \cup(\mathrm{G}, \mathrm{B})=(\mathrm{H}, \mathrm{C})$

\section{Definition 2.5}

Intersection of two fuzzy soft sets $(\mathrm{F}, \mathrm{A})$ and $(\mathrm{G}, \mathrm{B})$ in a soft class $(\mathrm{U}, \mathrm{E})$ is a fuzzy soft $\operatorname{set}(H, C)$ where $\mathrm{C}=\mathrm{A} \cap \mathrm{B}$ and 


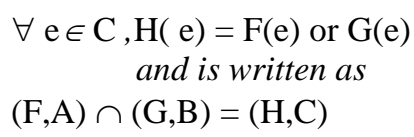

\section{Definition 2.6[1]}

If $(\mathrm{F}, \mathrm{A})$ and $(\mathrm{G}, \mathrm{B})$ are two soft sets, then $(\mathrm{F}, \mathrm{A}) \mathrm{AND}(\mathrm{G}, \mathrm{B})$ is denoted as $(\mathrm{F}, \mathrm{A}) \wedge(\mathrm{G}, \mathrm{B}) .(\mathrm{F}, \mathrm{A}) \wedge(\mathrm{G}, \mathrm{B})$ is defined as $(h, A \times B)$ where $h(a, b)=h_{a, b}=f_{a} \wedge g_{b}, \forall(a, b) \in A \times B$

\section{Fuzzy Soft Groups}

Aktas andÇagman [3] introduced the notion of soft groups, which extends the notion of group to include the algebraic structures of soft sets. A soft group is a parameterized family of subgroups. Now in this section we introduce the definition of fuzzy soft groups and give some fundamental properties of fuzzy soft groups.

\section{Definition 3.1: Soft Group[1]}

Let $\mathrm{X}$ be a group and $(\mathrm{F}, \mathrm{A})$ be a soft set over $\mathrm{X}$. Then $(\mathrm{F}, \mathrm{A})$ is said to be a soft group over $\mathrm{X}$ iff $\mathrm{F}(\mathrm{a})<\mathrm{X}$, for each $\mathrm{a} \in \mathrm{A}$.

\section{Definition 3.2: Fuzzy Soft Group [1]}

Let $\mathrm{X}$ be a group and (f, A) be a fuzzy soft set over X. Then (f, A) is said to be a fuzzy soft group over $X$ iff for each $a \in A$ and $x, y \in X$,
(i) $f_{a}(x \cdot y) \geq T\left(f_{a}(x), f_{a}(y)\right)$
(ii) $f_{a}\left(x^{-1}\right) \geq f_{a}(x)$

That is, for each $a \in A, f_{a}$ is a fuzzy subgroup in Rosenfeld's sense [10]

\section{Proposition 3.1}

Let (f, A) be a fuzzy soft set. Then (f,A) is a fuzzy soft group if and only if for each $a \in A$ and $x, y \in X$, $f_{a}\left(x \cdot y^{-1}\right) \geq T\left(f_{a}(x), f_{a}(y)\right.$

Proof.

For each $\mathrm{a} \in \mathrm{A}$ and $\mathrm{x}, \mathrm{y} \in \mathrm{X}$, by monotonicity of $\mathrm{T}$ and (ii) we have

$$
f_{a}\left(x \cdot y^{-1}\right) \geq T\left(f_{a}(x), f_{a}\left(y^{-1}\right)\right)
$$

$$
\geq T\left(f_{a}(x), f_{a}(y)\right)
$$

Conversely, first of all we have

$$
\begin{aligned}
\mathrm{f}_{\mathrm{a}}(\mathrm{e}) & =\mathrm{f}_{\mathrm{a}}\left(\mathrm{x} \cdot \mathrm{x}^{-1}\right) \\
& \geq \mathrm{T}\left(\mathrm{f}_{\mathrm{a}}(\mathrm{x}), \mathrm{f}_{\mathrm{a}}\left(\mathrm{x}^{-1}\right)\right) \\
& \geq \mathrm{T}\left(\mathrm{f}_{\mathrm{a}}(\mathrm{x}), \mathrm{f}_{\mathrm{a}}(\mathrm{x})\right) \text { by (ii) } \\
& =\mathrm{f}_{\mathrm{a}}(\mathrm{x}) .
\end{aligned}
$$

For each $\mathrm{x} \in \mathrm{X}$, where $\mathrm{e}$ is the unit element of $\mathrm{X}$.

\section{Furthermore,}

$$
\begin{aligned}
f_{a}\left(x^{-1}\right)=f_{a}\left(e \cdot x^{-1}\right) & \geq T\left(f_{a}(e), f_{a}\left(x^{-1}\right)\right) \\
& \geq T\left(f_{a}(e), f_{a}(x)\right) \\
& =f_{a}(x) .
\end{aligned}
$$

On the other hand, for each $\mathrm{a} \in \mathrm{A}$ and $\mathrm{x}, \mathrm{y} \in \mathrm{X}$,

$$
\begin{aligned}
\mathrm{f}_{\mathrm{a}}(\mathrm{x} \cdot \mathrm{y})=\mathrm{f}_{\mathrm{a}}\left(\mathrm{x} \cdot\left(\mathrm{y}^{-1}\right)^{-1}\right) & \geq \mathrm{T}\left(\mathrm{f}_{\mathrm{a}}\left(\mathrm{x}^{-1}\right), \mathrm{f}_{\mathrm{a}}\left(\mathrm{y}^{-1}\right)\right) \\
& \geq \mathrm{T}\left(\mathrm{f}_{\mathrm{a}}(\mathrm{x}), \mathrm{f}_{\mathrm{a}}(\mathrm{y})\right)
\end{aligned}
$$

This completes the proof.

\section{Proposition 3.2.[1]}

Let (f, A) be a fuzzy soft set and $\mathrm{e}$ is the unit element of $\mathrm{X}$. Then for each $\mathrm{a} \in \mathrm{A}$ and for each $\mathrm{x} \in \mathrm{X}$,
(1) $f_{a}\left(x^{-1}\right) \geq f_{a}(x)$
(2) $f_{a}(e)=f_{a}(x)$

\section{Proposition 3.3. [6]}

Let $f_{a}$ and $g_{a}$ be two fuzzy softgroups of $G$, then $f_{a} \cap g_{a}$ is fuzzy soft group of $G$.

\section{Proposition 3.4. [6]}

Let $f_{a}$ and $g_{a}$ be two fuzzy soft groups of $G$, then $f_{a} \cup g_{a}$ is fuzzy soft group of $G$. 


\section{Proposition 3.5.}

\section{Proof:}

Let $f_{a}$ and $g_{a}$ be two fuzzy soft groups over $G$, then $f_{a} \wedge g_{a}$ is fuzzy soft group of $G$.

Let $\mathrm{x}, \mathrm{y} \in \mathrm{G}$.

\section{FSG(i)}

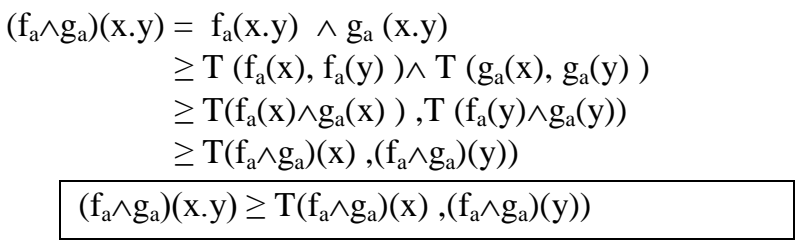

\section{FSG(ii)}

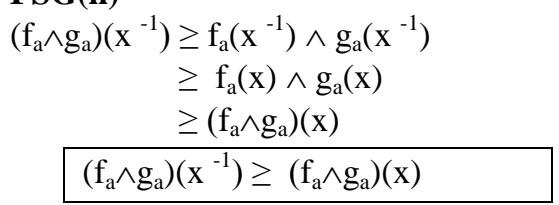

Proposition 3.6.

Proof:

Let $f_{a}$ be two fuzzy soft groups over $G$, then $f_{a}(x y)^{2}=f_{a}\left(x^{2} y^{2}\right)$ is fuzzy soft group of $G$.

FSG( i)

Let $\mathrm{x}, \mathrm{y} \in \mathrm{G}$.

$$
\begin{aligned}
\mathrm{f}_{\mathrm{a}}(\mathrm{x} \mathrm{y})^{2} & =\mathrm{f}_{\mathrm{a}}((\mathrm{x} \cdot \mathrm{y})(\mathrm{x} \cdot \mathrm{y})) \\
& \geq \mathrm{T}\left(\mathrm{f}_{\mathrm{a}}(\mathrm{x}, \mathrm{y}), \mathrm{f}_{\mathrm{a}}(\mathrm{x} \cdot \mathrm{y})\right) \\
& \geq \mathrm{T}\left(\mathrm{T}\left(\mathrm{f}_{\mathrm{a}}(\mathrm{x}), \mathrm{f}_{\mathrm{a}}(\mathrm{y})\right), \mathrm{T}\left(\mathrm{f}_{\mathrm{a}}(\mathrm{x}), \mathrm{f}_{\mathrm{a}}(\mathrm{y})\right)\right) \\
& \geq \mathrm{T}\left(\mathrm{T}\left(\mathrm{f}_{\mathrm{a}}(\mathrm{x}), \mathrm{f}_{\mathrm{a}}(\mathrm{x})\right), \mathrm{T}\left(\mathrm{f}_{\mathrm{a}}(\mathrm{y}), \mathrm{f}_{\mathrm{a}}(\mathrm{y})\right)\right) \\
& \geq \mathrm{T}\left(\mathrm{f}_{\mathrm{a}}(\mathrm{x} \cdot \mathrm{x}), \mathrm{f}_{\mathrm{a}}(\mathrm{y} \cdot \mathrm{y})\right) \\
& \geq \mathrm{T}\left(\mathrm{f}_{\mathrm{a}}\left(\mathrm{x}^{2}\right), \mathrm{f}_{\mathrm{a}}\left(\mathrm{y}^{2}\right)\right) \\
& =\mathrm{f}_{\mathrm{a}}\left(\mathrm{x}^{2} \mathrm{y}^{2}\right)
\end{aligned}
$$

FSG(ii) $f_{a}(x \text { y })^{-1} \geq T\left(f_{a}\left(x^{-1}\right), f_{a}\left(y^{-1}\right)\right)$

$$
\begin{aligned}
& \geq \mathrm{T}\left(\mathrm{f}_{\mathrm{a}}(\mathrm{x}), \mathrm{f}_{\mathrm{a}}(\mathrm{y})\right) \\
& =\mathrm{f}_{\mathrm{a}}(\mathrm{x} y)
\end{aligned}
$$

\section{Proposition 3.7:}

If $\left\{f_{a i}\right\}_{i \in f a}$ is a family of fuzzy soft groups of $G$, then $\cup f_{a i}$ is fuzzy soft group $G$ whose $\cup f_{a i}=\left\{\left(x, \vee f_{a i}(x) / x \in G\right\}\right.$, where $i \in f_{a}$.

Proof:

Let $x, y \in G$, then for $i \in f_{a}$, it follows that

(FSG(i))

$$
\begin{aligned}
\cup f_{a i}(x . y) & =\vee f_{a i}(x y) \\
& \geq \vee T\left(f_{a i}(x), f_{a i}(y)\right) \\
& \geq T\left(\left(\vee f_{a i}(x)\right),\left(\vee f_{a i}(y)\right)\right. \\
& \geq T\left(\left(\cup f_{a i}(x),\left(\cup f_{a i}(y)\right)\right.\right. \\
\cup f_{a i} & (x . y) \geq T\left(\left(\cup f_{a i}(x),\left(\cup f_{a i}(y)\right)\right.\right.
\end{aligned}
$$

\section{(FSG(ii))}

$$
\begin{aligned}
& \cup f_{\text {ai }}\left(x^{-1}\right)=\vee f_{a i}\left(x^{-1}\right) \\
& \geq \vee f_{a i}(x) \\
& \geq\left(\cup f_{a i}\right)(x) \\
&\left(\cup f_{a i}\right)\left(x^{-1}\right) \geq\left(\cup f_{a i}\right)(x)
\end{aligned}
$$

Hence $\left(\cup f_{a i}\right)$ is fuzzy soft group of $G$. 
Proposition 3.8:[6]

If $\left\{f_{\mathrm{ai}}\right\} \mathrm{i} \in_{\mathrm{f}}$ is a family of fuzzy soft groups of $\mathrm{G}$, then $\cap \mathrm{f}_{\mathrm{ai}}$ is fuzzy soft group $\mathrm{G}$ whose $\cap f_{a i}=\left\{\left(x, \wedge f_{a i}(x) / x \in G\right\}\right.$, where $i \in f_{a}$.

\section{Proposition 3.9:[6]}

Let $G$ and $G^{\prime}$ be two groups and $\theta: G \rightarrow G^{\prime}$ be a soft homomorphism. If $f_{a}$ is fuzzy soft group of $G$ then the pre-image $\theta^{-1}\left(f_{a}\right)$ is fuzzy soft group of $G$.

\section{Proposition 3.10 [6]}

Let $\theta: G \rightarrow G^{\prime}$ be an epimorphism and $f_{a}$ be fuzzy soft set in $G^{\prime}$. If $\theta^{-1}\left(f_{a}\right)$ is fuzzy soft group of $G, f_{a}$ is fuzzy soft group of G'.

\section{Proposition 3.11}

Proof:

Let $f_{a}$ be two fuzzy soft groups over $G$,and $\theta$ is endomorphism of $G$, then $f_{a}[\theta]$ is fuzzy soft group of G.

FSG(i)

Let $x, y \in G$

$$
\begin{aligned}
\mathrm{f}_{\mathrm{a}}([\theta](\mathrm{x} y)) & =\mathrm{f}_{\mathrm{a}}(\theta(\mathrm{x} \cdot \mathrm{y})) \\
& =\mathrm{f}_{\mathrm{a}}(\theta(\mathrm{x}) \cdot \theta(\mathrm{y})) \\
& \geq \mathrm{T}\left(\mathrm{f}_{\mathrm{a}}(\theta \mathrm{x}), \mathrm{f}_{\mathrm{a}}(\theta \mathrm{y})\right) \\
& \geq \mathrm{T}\left(\mathrm{f}_{\mathrm{a}}[\theta](\mathrm{x}), \mathrm{f}_{\mathrm{a}}[\theta](\mathrm{y})\right)
\end{aligned}
$$

$\mathrm{f}_{\mathrm{a}}([\theta](\mathrm{x} y)) \geq \mathrm{T}\left(\mathrm{f}_{\mathrm{a}}[\theta](\mathrm{x}), \mathrm{f}_{\mathrm{a}}[\theta](\mathrm{y})\right)$

FSG(ii)

$$
\begin{aligned}
\mathrm{f}_{\mathrm{a}}\left([\theta](\mathrm{x})^{-1}\right) & =\mathrm{f}_{\mathrm{a}}\left(\theta\left(\mathrm{x}^{-1}\right)\right) \\
& \geq \mathrm{f}_{\mathrm{a}}(\theta(\mathrm{x})) \\
& \geq \mathrm{f}_{\mathrm{a}}([\theta](\mathrm{x})) \\
\mathrm{f}_{\mathrm{a}}\left([\theta](\mathrm{x})^{-1}\right) & \geq \mathrm{f}_{\mathrm{a}}([\theta](\mathrm{x}))
\end{aligned}
$$

$\therefore \mathrm{f}_{\mathrm{a}}[\theta]$ is fuzzy soft group of $\mathrm{G}$

\section{Definition 3.3 [11]}

Let $X$ be a nonempty set. A fuzzy subset of $X$ is a function $\mu$ from $X$ into $[0,1]$.

\section{Definition 3.4 [12]}

A fuzzy subset of $G$ is called a fuzzy subgroup of $G$ if

$$
\mu(\mathrm{xy}) \geq \min \{\mu(\mathrm{x}), \mu(\mathrm{y})\}, \forall \mathrm{x}, \mathrm{y} \in \mathrm{G}
$$

$\mu(\mathrm{x}-1) \geq \mu(\mathrm{x}), \forall \mathrm{x} \in \mathrm{G}$. element of a group $\mathrm{G}$ by e .

\section{Definition 3.5 [11]}

Let $\mu \in \mathrm{SP}(\mathrm{G})$. Then $\mu$ is called a soft subgroup of $\mathrm{G}$, if

(1) $\mu(\mathrm{xy}) \supseteq \mu(\mathrm{x}) \cap \mu(\mathrm{y}), \forall \mathrm{x}, \mathrm{y} \in \mathrm{G}$ and

(2) $\mu(\mathrm{x}-1) \supseteq \mu(\mathrm{x}) \forall \mathrm{x} \in \mathrm{G}$.

Where $\mathrm{SP}(\mathrm{G})$ is denoted by soft power of $\mathrm{G}$, We denote the set of all soft subgroups of $\mathrm{G}$ by $\mathrm{S}(\mathrm{G})$.

\section{Definition 3.6 [12]}

Let $\mathrm{f}_{\mathrm{a}}$ be a fuzzy soft group $\mathrm{G}$. let $\mathrm{C}(\mathrm{x})=\left\{\mathrm{x} \in \mathrm{G} / \mathrm{f}_{\mathrm{a}}([\mathrm{xy}])=\mathrm{f}_{\mathrm{a}}(\mathrm{e}) \forall \mathrm{x} \in \mathrm{G}\right\}$. Then $C(\mathrm{x})$ is called fuzzy centralizer of $f_{a}$, where $[x y]$ is the commutator of two element $x, y$ in $G$

$$
\text { ie, }[x y]=x^{-1} y^{-1} x y
$$

\section{Proposition 3.12:}

Proof :

Let $\mathrm{f}_{\mathrm{a}}$ be a fuzzy soft group $\mathrm{G}$. and $\mathrm{n}$ be a natural number then $\mathrm{f}_{\mathrm{a}}\left((\mathrm{x} \mathrm{y})^{\mathrm{n}}\right)=\mathrm{f}_{\mathrm{a}}\left(\mathrm{x}^{\mathrm{n}} \mathrm{y}^{\mathrm{n}}\right) \quad \forall \mathrm{x}, \mathrm{y} \in \mathrm{C}(\mathrm{x})$

For every $\mathrm{x}, \mathrm{y} \in \mathrm{C}(\mathrm{x})$

$$
\begin{aligned}
& f_{a}\left((x y)^{n}\right)=f_{a}(x y \ldots \ldots x y x y x y) \\
& =f_{a}(x y \ldots \ldots x y x y x y .[1]) \\
& =f_{a}\left(x y \ldots \ldots x y y^{2} x\left[x^{-1} y^{-1} x y\right]\right) \\
& =f_{a}\left(x y \ldots \ldots x y y^{2} x[x, y]\right)
\end{aligned}
$$




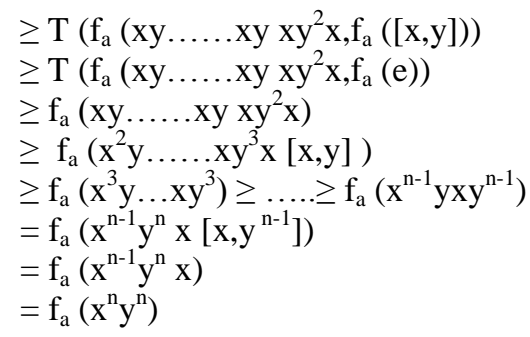

and

$$
\begin{aligned}
f_{a}\left(x^{n} y^{n}\right) & =f_{a}\left(x^{n-1} y^{n} x\right) \\
& =f_{a}\left(x^{n-1} y x y^{n-1}\left[y^{n-1}, x\right]\right) \\
& \geq f_{a}\left(x^{n-1} y x y^{n-1}\right) \geq \ldots . . f_{a}\left(x y \ldots . . x y x y^{2} x\right) \\
& =f_{a}(x y \ldots \ldots x y x y x y[x, y]) \\
& \geq f_{a}\left((x y)^{n}\right)
\end{aligned}
$$

Hence the result

\section{Conclusion}

In this paper we studied the algebraic properties of fuzzy soft sets in group structures. This work focused on fuzzy soft groups, homomorphism of fuzzy soft groups. To extend this work one could the properties of fuzzy soft sets in other algebraic structures such as rings, field and ideals.

\section{References}

[1] AbdülkadirAygüno_glu, HalisAygün,Introduction to fuzzy soft groups,computers and Mathematics with Applications 58,(2009) 1279_1286

[2] B.Ahmad and AtharKharal, "On Fuzzy Soft Sets", Advances in Fuzzy Systems,2009.

[3] Aktas. H and N. Cagman, Soft sets and soft group, Information Science 177 (2007), PP 2726-2735.

[4] G.J. Klir and B. Yuan, Fuzzy sets and fuzzy logic theory and applications, PretticeHelltic, New Jersey (1995).

[5] P.K.Maji, R.Biswas and A.R.Roy, "Fuzzy Soft Sets", Journal of Fuzzy Mathematics,9(3), 2001, 589-602.

[6] S.V.Manemaran, On Fuzzy Soft Groups ,International Journal of Computer Applications (0975 - 8887) Vol. 15- No.7, February 201138 .,

[7] D. Molodtsov, "Soft Set Theory - First Results", Comput. Math. Appl. No.37, PP 19-31, 1999

[8] RadenSulaiman, The Number of Fuzzy Subgroups of Group Defined by A Presentation, International Journal of

[9] Dr. P. Rajarajeswari and P. Dhanalakshmi, "An application of similarity measure of Fuzzy soft set based on distance", Journal of Mathematics, 4 (2012) 27-30.

[10] A. Rosenfeld, Fuzzy groups, Journal of Mathematical Analysis and Applications 35 (1971) 512517.

[11] Xia Yin, Study on Soft Groups, Journal of computers, vol. 8, no. 4, April 2013

[12] yunjiezhand and dong yu, On Fuzzy Abelian Subgroup, dalian maritime university, Liaoning.

[13] Yingying Liu, XiaolongXin, General fuzzy soft groups and fuzzy normal softGroups, annals of Fuzzy Mathematics and Informatics ,Volume 6, No. 2, (September 2013), pp. 391- 400 